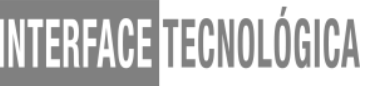

\section{VIABILIDADE ECONÔMICA DO CULTIVO DE BERINJELA}

\section{ECONOMIC FEASIBILITY OF BERINJELA CROP}

\author{
Letícia Mantovani - lelemantovanis2@hotmail.com \\ Igor Junior Jacyntho - igor.jacyntho@fatec.sp.gov.br
}

Selma de Fátima Grossi - grossi.selma@gmail.com

Faculdade de Tecnologia de Taquaritinga (FATEC) -SP -Brasil

DOI: 10.31510/infa.v16i2.679

\section{RESUMO}

A berinjela é muito conhecida por ser importante na saúde por ser fornecedora de muitas vitaminas como a Niacina (B5) dando proteção a pele e também ajudando a regular o sistema nervoso e o aparelho digestivo. Possui minerais como o cálcio, fósforo e ferro que o corpo humano precisa para realizar suas funções vitais. E através desse projeto será mostrado a viabilidade do cultivo da berinjela de doze meses com quatro ciclo de três meses cada canteiro, desde o clima que ela se desenvolve melhor, os tipos de solo que ela pode ser cultivada, o plantio das mudas, o espaçamento utilizado para plantar as mudas para ter espaço para o crescimento até a colheita. O processo adotado foi de, ao plantar o primeiro canteiro, após dois meses plantar o canteiro da área seguinte, fazendo uma sucessão para obter o aproveitamento total da produção durante o período proposto. E tabelas com custos de mudas e irrigação, custos com mão-de-obra e energia na área de aproximadamente $256 \mathrm{~m}^{2}$ foram confeccionadas para informar os materiais necessários. A partir dos custos das tabelas foram calculados e apresentados os valores do VPL ( $\$$ 53.540,61), Payback ( 1 ano e 2 meses) e a TIR com $(74,70 \%)$, comprovando a viabilidade do projeto.

Palavras-chave: Berinjela. Análise Econômica. VPL. PAYBACK. TIR.

\begin{abstract}
Eggplant is well known to be important in health as it provides many vitamins such as Niacin (B5) giving skin protection and also helping to regulate the nervous system and digestive tract. It has minerals like calcium, phosphorus and iron that the human body needs to perform its vital functions. And through this project will be shown the feasibility of growing the twelve-month eggplant with four three-month cycle each bed, from the climate it develops best, the types of soil it can be grown, the planting of seedlings, the spacing used to plant the seedlings to have room for growth until harvest. The process adopted was, when planting the first bed, after two months planting the bed of the next area, making a succession to obtain full use of production during the proposed period. And tables with seedling and irrigation costs, labor and energy costs in the area of approximately $256 \mathrm{~m}^{2}$ were made to inform the necessary materials. From the costs of the tables were calculated and presented the values of NPV (R \$ 53,540.61), Payback (1 year and 2 months) and IRR with (74.70\%), proving the viability of the project.
\end{abstract}




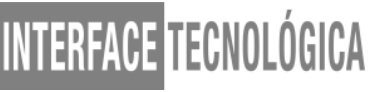

Keywords: Eggplant. Economic Analysis. NPV. PAYBACK. IRR.

\section{INTRODUÇÃO}

A berinjela é uma planta pertencente à família das solanaceae, possui características arbustivas com um caule semilenhoso, que pode alcançar altura superior a um metro (PORTAL SÃO FRANCISCO, s.d.). Segundo Antonini et al. (2002) há um crescente aumento no consumo desta hortaliça, motivada pela procura por parte dos consumidores de produtos mais saudáveis e com propriedades medicinais.

Por ser um alimento que pode ser consumido de várias formas, a berinjela também apresenta alto valor nutritivo como por exemplo é rica em vitaminas A,C, B1, B2 e B3 e possui também uma boa quantidade de sais minerais, tais como, potássio, cálcio, ferro, cobre e magnésio. Além disso seu consumo é bastante popular pela população brasileira e seu cultivo por olericultores é comumente realizado fazendo com que esta cultura tenha fortes concorrentes no mercado (PORTAL SÃO FRANCISCO, s.d.)

Todo produtor, ao iniciar a atividade de produção de berinjelas, consequentemente será afetado pelas barreiras de entrada de outros produtores, no qual passará a concorrer por qualidade, melhor prestação de serviços, preços e clientes. Antonini et al. (2002) afirma que o mercado brasileiro tem se tornado cada vez mais exigente quanto à qualidade do produto e o preço.

O mercado consumidor da berinjela não se restringe a um pequeno grupo, uma vez que o produto pode ser preparado de várias formas (crua, cozidas em água, refogadas em óleo, saladas, fritas e/ou assadas), tendo assim grande aceitação no momento do consumo.

Em razão da grande demanda pela produção da berinjela foi realizado um projeto com a intenção de suprir a demanda de consumo da cidade de Taquaritinga e região, no qual estas possuem nível considerável de consumo.

O presente trabalho teve o objetivo de analisar a viabilidade econômica da produção de berinjelas num período de doze meses em uma área de aproximadamente $256 \mathrm{~m}^{2}$ no município de Taquaritinga/SP. Para ter discernimento dos valores a serem gastos com a produção foram elaboradas tabelas com os preços referentes a cada gasto a se ter com a mesma. 


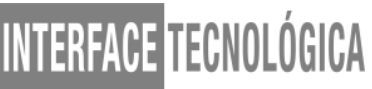

\section{REFERENCIAL TEÓRICO}

Pesquisas apontam o surgimento da berinjela na Índia e na China, sendo disseminada pelos árabes através da Europa durante o período da Idade Média (PORTAL SÃO FRANCISCO, s.d.).

No Brasil a berinjela teve sua inserção por volta do século XVI, pelos portugueses. A mesma é produzida em grande escala no Brasil nos estados de São Paulo, Rio de Janeiro e Paraná, a região que se tem o maior índice de consumo é no estado de São Paulo (PORTAL SÃO FRANCISCO, s.d.).

Em meados de 1937 e 1940, no Instituto Agronômico de Campinas (IAC), teve início as pesquisas, com a segmentação e elaboração de sementes, e os primeiros ensaios para a introdução mais adequada da berinjela (EMBRAPA HORTALIÇAS, s.d.).

Ela chega atingir um metro de altura, com flores roxas. Tem o toque macio, alongados e ovais e $50 \%$ do volume da berinjela é ar, é uma boa fonte de sais minerais e vitaminas pois possuem proteína, cálcio, ferro e fósforo (GLOBO RURAL, 2006).

A berinjela tem grande importância na saúde, através da Niacina (vitamina B5), dando proteção a pele e ajudando a regular o sistema nervoso e aparelho digestivo. Possui minerais como Cálcio, Fósforo e Ferro, podendo apresentar resultados através de uma boa formação dos ossos, dentes, músculos e até mesmo ajudando em uma boa coagulação do sangue (PORTAL SÃO FRANCISCO, s.d.).

É conhecida por ser um vegetal com um grande poder na diminuição do colesterol e destaca-se também na ajuda na diminuição da gordura sobre o fígado (PORTAL SÃO FRANCISCO, s.d.).

A berinjela é apreciada em diferentes culturas, é o principal ingrediente de comidas típicas da cozinha mediterrânea, indiana, francesa e de países do oriente médio. O legume se espalhou pelo mundo a partir das suas origens nas zonas tropicais da China e da Índia (GLOBO RURAL, 2006).

\subsection{Clima}

A berinjela é originária de clima tropical e subtropical, desenvolvendo-se melhor nas regiões de clima quente com temperaturas médias diurnas de $25^{\circ} \mathrm{C}$ a $35^{\circ} \mathrm{C}$ e noturnas de $20^{\circ} \mathrm{C}$ 
a $27^{\circ} \mathrm{C}$ e com umidade relativa do ar de $80 \%$. Trabalhando nessas condições, a berinjela pode ser cultivada durante todo o ano. Nos locais de temperatura média inferior a $18^{\circ} \mathrm{C}$ no inverno, recomenda-se o plantio na primavera ou verão (EMBRAPA HORTALIÇAS, s.d.).

As temperaturas elevadas são mais favoráveis no período da germinação, emergência e estádio inicial de formação de mudas. Os locais com temperatura média abaixo de $14^{\circ} \mathrm{C}$ inibem o crescimento, floração e frutificação; locais acima de $32^{\circ} \mathrm{C}$ aceleram a maturação dos frutos e, acima de $35^{\circ} \mathrm{C}$ por período prolongado, inviabilizam o pólen, assim impedindo a plena fertilização e resultando em frutos defeituosos. As temperaturas noturnas abaixo de $16^{\circ} \mathrm{C}$ resultam no crescimento retardado das plântulas, porém, uma vez estabelecida, a cultura passa a ter resistência ao frio (EMBRAPA HORTALIÇAS, s.d.).

Considera-se muito boa sua tolerância à seca e umidade excessiva, mesmo que não seja considerada cultura de hábito perene e quando é submetida à poda após o primeiro ano de produção, a berinjela rebrota o início de um novo ciclo de produção (EMBRAPA HORTALIÇAS, s.d.).

\subsection{Solo}

Segundo EMBRAPA HORTALIÇAS a berinjela pode ser cultivada em diversos tipos de solos, desde os arenosos até os mais argilosos. Entretanto, desenvolve-se melhor em solos de textura média, profundos, ricos em matéria orgânica, com boa retenção de umidade e bem drenados, uma vez que a cultura não tolera encharcamento.

Antes do preparo do terreno, deve-se retirar amostras de solo da camada de 0-20 cm e, quando possível, da camada subsuperficial (20-40 cm), para realização de análises químicas, imprescindíveis à adequada recomendação de corretivos e fertilizantes se necessário (EMBRAPA HORTALIÇAS, s.d.).

O preparo do solo respalda-se em uma a duas arações e duas gradagens. A aração deve atingir a profundidade de $30 \mathrm{~cm}$, sendo seguida por uma gradagem de nivelamento.

EMBRAPA HORTALIÇAS afirma que,

O plantio da berinjela pode ser realizado em sulcos ou covas. O sulco deve ter aproximadamente $20 \mathrm{~cm}$ de profundidade. O espaçamento é de 1 a $1,5 \mathrm{~m}$ entre fileiras e de 0,7 a 1,0 m dentro da fileira. Para as cultivares híbridas atuais, que apresentam plantas extremamente vigorosas, ou quando se pretende prolongar o período de colheita deve-se optar pelos maiores espaçamentos. A muda deve ser 
transplantada na mesma profundidade da sementeira, sem enterrar o coleto para evitar a podridão-do-colo.

\subsection{Plantio}

Para obter mudas sadias e vigorosas, as mesmas têm que ser de produção própria ou adquirida com viveiristas idôneos, para que a cultura da berinjela seja de sucesso (EMBRAPA HORTALIÇAS, s.d.).

Para o agricultor produzir suas próprias mudas, ele deve procurar casas especializadas para efetuar as compras das sementes. Sempre verificar quando comprar se é de empresa idônea, se é da cultivar desejada, os índices de germinação e pureza e a data de validade da análise e outras informações da embalagem (EMBRAPA HORTALIÇAS, s.d.).

Ao adquirir as mudas, deve se procurar viveiristas reconhecidos e que possam assegurar a qualidade e a sanidade das mudas, assim como sua pureza varietal. Ao receber as mudas, sempre verificar o tamanho, a sanidade e o vigor da planta (EMBRAPA HORTALIÇAS, s.d.).

Para produzir as suas próprias mudas, pode se também optar pelo sistema das sementeiras, copinhos ou bandejas.

As sementes podem ser deixadas na água por um dia para facilitar a germinação. Semeie as sementes na superfície do solo, cobrindo-as com uma leve camada de terra. As sementes também podem ser semeadas em sementeiras ou saquinhos de plástico, realizando o transplante das mudas quando estas estão com 8 a $10 \mathrm{~cm}$ de altura. A germinação das sementes geralmente ocorre em uma ou duas semanas (EMBRAPA HORTALIÇAS, s.d.).

O espaçamento ideal para o plantio pode varia com o porte da cultivar e o clima da região podendo variar de $60 \mathrm{~cm}$ a $1 \mathrm{~m}$ entre as linhas de plantio e de $50 \mathrm{~cm}$ a $1 \mathrm{~m}$ entre as plantas (EMBRAPA HORTALIÇAS, s.d.).

\subsection{Controle de Pragas e doenças}

A berinjela é muito resistente ao ataque de pragas, mas pode se prevenir, pois está sujeita á vários insetos/pragas como percevejo do tomate, percevejo rendado, ácaros, lagartadas-solanáceas, pulgão, mosca branca e entre outros, quando aparecem poucas pragas é possível ser retirado manualmente. Mas caso a invasão esteja difícil controlar manualmente, 


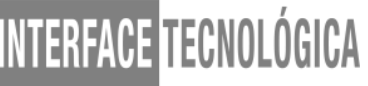

deve ser usado repelentes orgânicos, usar fitas e placas adesivas atrativas e também pode-se usar joaninhas pois ela se alimenta dos insetos dos cultivos (DA HORTA PRA PANELA, s.d.)

A doença mais preocupante é a murcha, ela é bacteriana ou fungal, quando alojada, pode determinar o fim de uma planta. Para que seja evitada essa doença, a berinjela tem que ser irrigada sem excesso, estar bem nutrida, garantir exposição necessária ao sol e sempre manter o cultivo limpo. Quando demonstrar sintomas nas folhas, frutos apodrecidos e escurecimento do caule, deve eliminar imediatamente as partes contaminadas, mas se for mais grave deve eliminar todo o cultivo e renovar a terra antes de plantar (DA HORTA PRA PANELA, s.d.)

\section{MATERIAIS E MÉTODOS}

Este projeto teve o intuito de verificar a viabilidade do plantio de berinjelas orgânicas num período de doze meses com quatro ciclos de três meses cada canteiro, abrangendo desde o preparo do solo e manejo até a colheita.

Considerando o tamanho da área de $256 \mathrm{~m}^{2}$ está foi dividida em três canteiros no qual cada um com trinta e três metros de comprimento com 1,30 m de largura. O espaçamento adotado para o plantio foi de $60 \mathrm{~cm}$ entre as linhas de plantio e de $50 \mathrm{~cm}$ entre as plantas conforme manual de orientação EMBRAPA HORTALIÇAS. Cada canteiro contou com duas fileiras de plantas, tendo 60 pés em cada uma.

Ao redor do canteiro foram dispostos caminhos de 1 metro de largura e em um dos lados com 3 metros de largura, pois no local onde estava disposta a caixa d'água responsável pela irrigação da cultura.

Visando o melhor aproveitamento da área disponível, ao fazer essa divisão entre os canteiros, o processo adotado foi de, ao plantar o primeiro canteiro, após dois meses plantar o canteiro da área seguinte, fazendo uma sucessão para obter o aproveitamento total da produção durante o período proposto.

A metodologia utilizada para as análises dos índices econômicos VPL e TIR foi o programa EXCEL, que permitiu a construção de planilhas referentes aos custos, despesas e receitas. 


\subsection{Custo das despesas}

A seguir estão apresentadas as tabelas (1, 2, 3, 4 e 5) com os custos para a produção das berinjelas numa área de $256 \mathrm{~m}^{2}$. No ato das compras foram calculados alguns produtos para compra em quantidade maior, tendo em vista por exemplo as sementes que, pode ocorrer de algumas não germinarem, assim já terá em mãos uma quantidade maior para substitui-las.

Tabela 1 - Despesas com produção das mudas e irrigação

\begin{tabular}{c|c|c|rr|rr}
\hline Despesas & Unid. & Quant. & \multicolumn{2}{|c|}{ Preço Unit. } & \multicolumn{2}{c}{ Preço Total } \\
\hline Bomba d'água submersa & $\mathrm{Pç}$ & 1 & $\mathrm{R} \$$ & 339,00 & $\mathrm{R} \$$ & 339,00 \\
\hline Mangueira de gotejamento 3.5mt & $\mathrm{Mt}$ & 2 & $\mathrm{R} \$$ & 850,00 & $\mathrm{R} \$$ & $1.700,00$ \\
\hline Caixa d'água - 1.000L & $\mathrm{Pc}$ & 1 & $\mathrm{R} \$$ & 299,00 & $\mathrm{R} \$$ & 299,00 \\
\hline Disjuntor & $\mathrm{Pç}$ & 2 & $\mathrm{R} \$$ & 6,99 & $\mathrm{R} \$$ & 13,98 \\
\hline Torneira & $\mathrm{Pç}$ & 2 & $\mathrm{R} \$$ & 35,00 & $\mathrm{R} \$$ & 70,00 \\
\hline Conexões cano pvc & $\mathrm{Pç}$ & 2 & $\mathrm{R} \$$ & 8,39 & $\mathrm{R} \$$ & 16,78 \\
\hline Cano pvc & $\mathrm{Pc}$ & 34 & $\mathrm{R} \$$ & 13,99 & $\mathrm{R} \$$ & 475,66 \\
\hline Conexões gotejamento & $\mathrm{Pç}$ & 60 & $\mathrm{R} \$$ & 2,90 & $\mathrm{R} \$$ & 174,00 \\
\hline Saco plástico para mudas - & & & & & & \\
500unid. & $\mathrm{Pç}$ & 15 & $\mathrm{R} \$$ & 27,00 & $\mathrm{R} \$$ & 405,00 \\
\hline Semente - pct com 200 unid. & $\mathrm{Pct}$ & 36 & $\mathrm{R} \$$ & 27,00 & $\mathrm{R} \$$ & 972,00 \\
\hline Total & & & & & R\$ & $\mathbf{4 . 4 6 5 , 4 2}$ \\
\hline
\end{tabular}

Fonte: Elaborado pelos autores 2019.

Para a produção, além dos custos variáveis, também foram projetados para os doze meses os custos fixos que envolvem mão-de-obra e energia elétrica. Para que haja melhor execução do projeto foi necessário que o produtor possuísse em sua propriedade poço semiartesiano ou artesiano para a utilização das mangueiras de gotejamento para irrigação.

Tabela 2 - Custos com mão-de-obra

\begin{tabular}{c|c|c|cc}
\hline Custos Mensais & Quant. & $\begin{array}{c}\text { Valor Mensal } \\
\text { unitário }\end{array}$ & $\begin{array}{c}\text { Total no 12 } \\
\text { Meses }\end{array}$ \\
\hline Mão-de-Obra & 2 & $\mathrm{R} \$ \quad 998,00$ & $\mathrm{R} \$$ & $23.952,00$ \\
\hline \multicolumn{5}{c}{ Fonte: Elaborado pelos autores 2019. }
\end{tabular}

Tabela 3 - Custos com energia

\begin{tabular}{c|c|c|c}
\hline Quant & Preço & Valor Total & Valor Total \\
KWh & KWh & Mensal & Anual \\
\hline
\end{tabular}




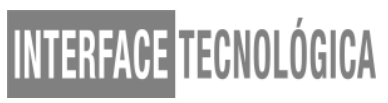

\begin{tabular}{l|c|cc|cc}
\hline 45 & 0,4836 & $\mathrm{R} \$$ & 21,76 & $\mathrm{R} \$$ & 261,14 \\
\hline \multicolumn{6}{c}{ Fonte: Elaborado pelos autores 2019. }
\end{tabular}

Tabela 4 - Custo total de produção

\begin{tabular}{c|rr}
\hline Custos & \multicolumn{2}{|c}{ Valor Total } \\
\hline Despesas & $\mathrm{R} \$$ & $4.465,42$ \\
\hline Mão-de-obra & $\mathrm{R} \$$ & $23.952,00$ \\
\hline Energia & $\mathrm{R} \$$ & 261,14 \\
\hline Total & $\mathrm{R} \$$ & $28.678,56$ \\
\hline
\end{tabular}

Fonte: Elaborado pelos autores 2019.

Tabela 5 - Custo total de produção

\begin{tabular}{|c|c|c|c|c|c|}
\hline Produto & $\begin{array}{c}\text { Estimativa de } \\
\text { produção } \\
\text { Kg/pé }\end{array}$ & Preço/Kg & $\begin{array}{l}\text { Quantidade } \\
\text { de Pés }\end{array}$ & Total por ciclo & Total ciclos (4) \\
\hline Berinjela & 12 & $\mathrm{R} \$ \quad 1,80$ & 480 & $10.368,00$ & $41.472,00$ \\
\hline
\end{tabular}

\section{RESULTADOS E DISCUSSÃO}

Para saber quando o Fluxo de Caixa $(\mathrm{FC})=$ Receita - (custos + despesas) foram realizados os cálculos da pesquisa através dos resultados obtidos com VPL, PAYBACK e TIR o projeto foi considerado viável, devido VPL ter apresentado valor positivo ( $\mathrm{R} \$ 53.540,61)$ pois segundo Sanches et al. (2008) sabe-se que um VPL acima de zero indica o mínimo de recuperação do capital investido, seguido dos demais resultados PAYBACK Simples que é um dos métodos mais simples para ser analisado a viabilidade de um investimento ( 1 ano e 2 meses) e PAYBACK Descontado que considera descontados ou seja, fluxos trazidos ao valor presente com a taxa de juros, a fim de saber quando os fluxos de caixa pagam o investimento inicial ( 1 ano e 3 meses).

A TIR é utilizada em comparação a uma taxa de juros esperada para um investimento, esta demonstra que quando ela é maior que a TMA o projeto é considerado viável e quando é menor que a TMA o projeto é considerado inviável. 


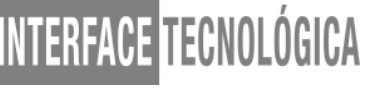

Optou se pela TIR, como indicador de rentabilidade, pois esta leva em conta a variação do capital ao longo do tempo e a tentativa de estimar e avaliar a taxa de atratividade (SANCHES et al., 2008). A TIR permite mostrar a situação do caixa da atividade e constitui o resultado para cobrir demais custos fixos, riscos, retorno do capital e capacidade empresarial (MARTIN et al., 1994).

O projeto apresentou a TIR de $74,70 \%$ sendo esse resultado maior que a TMA utilizada $(6,5 \%)$.

\section{CONSIDERAÇÕES FINAIS}

Após a análise dos custos a partir do cálculo do VPL, Payback e TIR, o projeto indicou haver viabilidade, apresentando lucratividade e taxa de retorno relativamente satisfatória.

Para tanto, conclui-se que o tempo de retorno do investimento feito será num prazo estimado de 1 ano e 2 meses, ressaltando que o período proposto para o projeto é de 4 anos.

Vale ressaltar que, durante o período estabelecido para o projeto os custos maiores são os custos fixos projetados para os doze meses que são os gastos com mão-de-obra e energia.

O projeto envolve um investimento com valor considerável, porém com indicação de bom retorno do mesmo.

\section{REFERÊNCIAS}

ANTONINI, A.C.C.; ROBLES, W.G.R.; TESSARIOLI NETO, J.; KLUGE, R.A. Capacidade produtiva de cultivares de berinjela. Horticultura Brasileira, Brasília, v. 20, n. 4, p. 646-648, dezembro 2002.

BERINJELA. Portal São Francisco. s.d. Disponível em: < https://www.portalsaofrancisco.com.br/alimentos/berinjela> Acesso em : jul. 2019.

BERINJELA PRODUÇÃO/PRODUTIVIDADE. A Feira. s.d. Disponível em: <http://www.ufrgs.br/afeira/materias-primas/hortalicas/berinjela/producao-produtividade>. Acesso em: 05 jul. 2019.

BERINJELA ORGÂNICA E SUCULENTA NA SUA HORTA. Da horta pra panela. S.d. Disponível em:<https://dahortaprapanela.com.br/plante-berinjela-em-casa/>. Acesso em: 29 ago. 2019. 


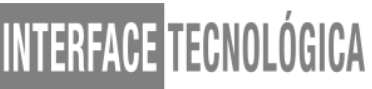

COMO PLANTAR BERINJELA. CLIMA PROPICIO PARA O PLANTIO DA BERINJELA. SISTEMAS DE PRODUÇÃO 3. Embrapa Hortaliças. s.d. Disponível em: <https://www.embrapa.br/hortalicas/berinjela/clima>._Acesso em: 13 jul. 2019.

COMO PLANTAR BERINJELA. Globo Rural 2006. Disponível em: < https://revistagloborural.globo.com/vida-na-fazenda/como-plantar/noticia/2018/04/comoplantar-berinjela.html> . Acesso em: 10 jul. 2019.

COMO PLANTAR BERINJELA. Hortas. Info. s.d. Disponível em: <https://hortas.info/como-plantar-berinjela>. Acesso em: 07 jul. 2019.

COMO PLANTAR BERINJELA. PRINCIPAIS CULTIVARES DE BERINJELA NO MERCADO. SISTEMAS DE PRODUÇÃO 3. Embrapa Hortaliças .s.d. Disponível em: <https://www.embrapa.br/hortalicas/berinjela/cultivares>. Acesso em: 13 jul. 2019.

COMO PLANTAR BERINJELA. SISTEMAS DE PRODUÇÃO 3. Embrapa Hortaliças. s.d. Disponível em: <https://www.embrapa.br/hortalicas/berinjela/processamento>. Acesso em: 07 jul. 2019.

COMO PLANTAR BERINJELA. SOLOS. SISTEMAS DE PRODUÇÃO 3. Embrapa Hortaliças. s.d._Disponível em:_<https://www.embrapa.br/hortalicas/berinjela/solos>. Acesso em: 13 jul. 2019.

COTAÇÃO DE PREÇOS. Ceasa Campinas. 2019. Disponível em:

<http://www.ceasacampinas.com.br/cotacoes-anteriores>. Acesso em: 31 ago. 2019.

CULTIVO DA BERINJELA (SOLANUMMELONGENA L.). Ribeiro, C. S. Da C.; Brune, S.; Reifschneider, F. J. B. Embrapa Hortaliças. Disponível em: <https://www.embrapa.br/hortalicas/busca-de-publicacoes/-/publicacao/765608/cultivo-daberinjela-solanum-melongena-1>. Acesso em: 05 jul. 2019.

MARTIN, N. B. SERRA, R. ANTUNES, J. F. G. OLIVEIRA, M. D. M. OKAWA, H. Custos: sistema de custo de produção agrícola. Informações Econômicas, São Paulo, v. 24, n. 9, p 97-122, set. 1994.

SANCHES, E.G.; SECKENDORFF, R.W.V.; HENRIQUE, M.B. et al. Viabilidade econômica do cultivo de bijupirá (Rachycentron canadum) em sistema offshore. Informações Econômicas, v.12, n.38, p.41-51, 2008. 